\title{
Predictive value of sputum cytology
}

\begin{abstract}
A 60 year old woman non-smoker with bronchial asthma of 6 years' duration, treated with aminophylline, salbutamol, and oral corticosteroids, was admitted because of increasing dyspnoea and productive cough. On examination she was in moderate respiratory distress with inspiratory and expiratory wheezes. Her chest radiograph was interpreted as normal. Two consecutive sputum examinations requested by a junior doctor reveal "malignant" cells.
\end{abstract}

There is a general agreement that a finding of malignant cells in the sputum of a person with a normal chest radiograph warrants fibreoptic bronchoscopy to locate the malignant tumour with a view to subsequent surgical removal. ${ }^{12}$ This recommendation is based on the inverse correlation between survival after surgical treatment of lung cancer and stage of the tumour. It has been reported that $24-42 \%$ of patients with stage I disease were alive at six years, whereas only $10 \%$ of those with stage II or III survived for five years. ${ }^{3}$ The best survival figures after surgical resection have been reported in symptom free patients with radiologically occult disease detected by positive sputum cytology. ${ }^{4-8}$ Even if we allow for the effect of "lead time" (whereby a longer survival noted in those diagnosed earlier is explained by a longer period of observation of the disease rather than by alteration in its course) most clinicians would still favour diagnosis of bronchial carcinoma at the earliest stage possible.

It has been claimed that "exfoliative cytology is a definitive diagnostic test for lung cancer,"9 and that its accuracy has advanced to the point "that the term 'exfoliative' cytology should be replaced by 'diagnostic' cytology". ${ }^{10}$ Malignant cells have, however, been found in the sputum in up to $10.3 \%{ }^{9}$ of cases in the absence of lung cancer, mainly among patients with pulmonary infections ${ }^{911}$ and bronchial asthma. ${ }^{12}$ How certain is the diagnosis of lung cancer in a symptomless person with a normal chest radiograph and malignant cells in the sputum? Or, in other words, what is the positive predictive value of sputum cyto-

Address for reprint requests: Dr J Benbassat, Department of Medicine, Hadassah University Hospital at Mount Scopus, POB 24035 91240 Jerusalem, Israel.

Accepted 18 November 1986 logy for lung cancer in the absence of other indicators of malignancy?

The predictive value of a test depends on its reliability, sensitivity, and specificity, and on the prevalence of the disease in the population from which the patient is drawn ("pretest probability" or "prior probability of disease"). ${ }^{13}$ The reliability of a test is defined as its precision. A reliable test is one which, when applied repeatedly to the same specimen or patient, will produce the same or a similar result. Test reliability is commonly expressed in terms of its reproducibility. Test sensitivity is defined as the proportion of persons with a given disease who give a positive response to the test. The specificity of a test is defined as the proportion of persons without the disease who give a negative response to the test. There is a tendency to confuse test sensitivity with positive predictive value, which is defined as the proportion of persons giving a positive response to the test who have the disease. The term "false positive" rate is often incorrectly defined as the ratio between false positive and true positive test results. The correct definition of a false positive rate is the proportion of persons without the disease who give a positive response to the test. Thus false positive rate $=1-$ specificity.

The following is a review of published data on the reliability, sensitivity, and specificity of sputum cytology for lung cancer, in an attempt to estimate the positive predictive value of a finding of malignant cells in the sputum in a symptomless person with a normal chest radiograph. The pretest probability of preclinical lung cancer is derived from lung cancer incidence rates and from estimates of the duration of the presymptomatic phase of lung cancer.

\section{Reliability of pulmonary cytology}

\section{REVERSIBILITY OF ABNORMALITIES IN SPUTUM CYTOLOGY}

The cytological abnormalities of sputum are usually classified as mild, moderate, and marked atypia, and positive identification of carcinoma cells. ${ }^{5-7}$ Studies have indicated a sequential progression from mild to moderate and severe atypia, carcinoma in situ, and invasive cancer. ${ }^{14-16}$ It is believed that the earlier stages of this sequence are reversible. Evidence that 
Table 1 Abnormalities detected in sputum cytological screening programmes of populations at high risk of lung cancer

\begin{tabular}{|c|c|c|c|c|c|}
\hline \multirow[b]{2}{*}{ Author } & \multirow[b]{2}{*}{ Population at risk } & \multicolumn{4}{|c|}{ Number of cases with abnormal cytology by degree of cell atypia } \\
\hline & & $\begin{array}{l}\text { Normal or } \\
\text { mild atypia }\end{array}$ & $\begin{array}{l}\text { Moderate } \\
\text { atypia }\end{array}$ & $\begin{array}{l}\text { Marked } \\
\text { atypia }\end{array}$ & $\begin{array}{l}\text { Cance } \\
\text { cells }\end{array}$ \\
\hline Frost et $a l^{5}$ & Male smokers age 45 years or more & 4984 & 169 & 14 & 11 \\
\hline Flehinger et $\mathrm{al}^{6}$ & Male smokers age 45 years or more & 4843 & 28 & 8 & 14 \\
\hline Fontana et $^{\mathrm{al}^{7}}$ & Male smokers age 45 years or more & 10061 & 24 & 5 & 27 \\
\hline \multirow[t]{2}{*}{ Saccomanno et al ${ }^{14}$} & Smoking uranium miners & 1294 & 745 & 279 & 31 \\
\hline & Non-smoking uranium miners & 877 & 272 & 59 & 0 \\
\hline Hayata et al ${ }^{18}$ & Smokers, age 40 years or more & 548 & 13 & 2 & 1 \\
\hline Kotin and Paul ${ }^{19}$ & Asbestos workers & 11099 & 77 & 8 & 8 \\
\hline Kobusch et al ${ }^{20}$ & Asbestos workers & 700 & 10 & - & 4 \\
\hline \multirow[t]{3}{*}{ Band et $a^{21}$} & Smoking uranium miners & 163 & 36 & 9 & 2 \\
\hline & Non-smoking uranium miners & 36 & 2 & 0 & 1 \\
\hline & Smoking non-miners & 89 & 9 & 1 & 1 \\
\hline
\end{tabular}

not all cases of moderate atypia end in lung cancer has been presented in experimental models showing that vitamin A deficiency induces reversible squamous cell metaplasia ${ }^{17}$ and in longitudinal studies in man. ${ }^{14-16}$ Surveys of sputum cytology in populations at risk of lung cancer have shown that cases of mild and moderate cell atypia outnumber those with carcinoma cells in their sputum (table 1). The differences in prevalence of moderate atypia and cancer cells cannot be accounted for by differences in the length of these stages. ${ }^{15}$ It may therefore be inferred that in some cases moderate atypia is a reversible abnormality in sputum cytology.

While mild and moderate degrees of atypia are thought to be reversible, there is uncertainty about the reversibility of marked atypia. Saccomanno et $a l^{14}$ have stated that "while following subjects with marked atypia it has been observed that very few, if any, return to milder atypia without subsequently reverting to marked. This has led us to postulate that severe atypia may represent an irreversible step in the progression to carcinoma." A similar conclusion may be drawn from the results of the National Cancer Institute Cooperative Early Lung Cancer Detection Program, ${ }^{4-8}$ which indicate that marked atypical cells have a specificity of $99.94 \%$ for histologically proved cancer. On the other hand, it has been reported that follow up of 10 persons with marked atypia by repeated cytological examination of the sputum and selective fibreoptic bronchoscopy every three months for three years detected cancer in one case after six months, in another after 13 months, and in a third after 24 months. The remaining seven reverted to lesser degrees of atypia during follow up of 24-72 months. ${ }^{22}$

\section{REPRODUCIBILITY OF INTERPRETATION OF} SPUTUM CYTOLOGY

The contradictory observations on the reversibility of marked atypia are probably related to different patterns of recognition and classification of cytological abnormalities. Despite repeated efforts to estab- $\overrightarrow{\mathcal{F}}$ lish morphological criteria for classification of atypia, ${ }^{1423}$ experts seem to differ in their inter- pretation of detected cytological abnormalities. A rez view of published surveys of sputum cytology in populations at high risk of lung cancer ${ }^{5-71418-215}$ revealed that the ratio between the numbers of speci-0 mens classified as showing marked atypia and those believed to contain carcinoma cells varied from $0 \cdot 2: 1_{0}$ to $9: 1$; the ratio between moderate atypia and car-o cinoma cells varied from $2: 1$ to $32: 1$. Even within the National Cancer Institute Cooperative Early Lungo Cancer Detection Program, ${ }^{5-7}$ there were consid-ळ erable differences in the relative numbers of specimens interpreted as containing cells with moderate atypia, marked atypia, and carcinoma cells (table 1).

We know of only one study of interobserver re producibility in the interpretation of sputum cytological findings. Evans and Shelley ${ }^{24}$ asked a panel of independent experts to reexamine 120 sputum cytol ogy slides provided by six hospital centres, and clas $-x$ sify them into the following categories of cell atypia: 3 1-normal; 2-hyperplasia, squamous metaplasia, or changes of the order seen in inflammation; 3 -dyskaryosis or atypical metaplasia; 4 -suggestive of malignancy; and 5-diagnostic of malignancy? Each hospital centre that provided the slides was asked that those originally classified in categories and 5 should have histological or clinica confirmation or both. The "gold standard" for then remaining categories of cell atypia was a consensus diagnosis, reached by discussion among the experts $\mathrm{s}^{\omega}$ after each of them had submitted his own diagnosis. "False positives" were defined as expert diagnoses of grade 4 or 5 in a slide whose consensus diagnosis wase normal or grade 2. "False negatives" were expert diagnoses of "normal" or grade 2 in a slide originally diagnosed by the providing centre as grade 4 or 5 . The्⿱ results indicated an average false positive rate of $1.3 \%$, an average false negative rate of $5 \%$, and an overall disagreement on the degree of cell atypia o 
$\mathbf{9} \cdot 3 \%$. Most participating experts reported difficulties in examining slides prepared by unfamiliar techniques. ${ }^{24}$

It is uncertain therefore whether the limited specificity of lower degrees of atypia is due to reversal to lesser degrees of atypia or to observer error. The following analysis is based on the assumption that mild and moderate atypia are a non-specific response to irritation, and not a definitive indicator of malignancy. On the other hand, marked atypia and cancer cells in the sputum are considered as increasingly more specific indicators of cancer.

\section{Sensitivity and specificity of sputum cytology}

We searched publications in English since 1960 for data from which the specificity or sensitivity of sputum cytology in the diagnosis of lung cancer could be calculated. A review of 22 articles $^{5-79-1125-40}$ revealed that malignant cells have been found in $28 \cdot 6^{40}$ to $88.9 \% 9$ of patients with histologically proved cancer, and in $0.005 \%^{5-7}$ to $10.3 \%{ }^{9}$ of subjects without lung cancer (table 2).
The variability of the reported sensitivity values is probably due to differences in tumour location and number of repeat sputum specimens examined. Sensitivity increases with repeated examinations ${ }^{39}$ and is highest in tumours located in the main bronchi. ${ }^{113031373840}$ The variability in reported specificity is probably due to interobserver differences in degrees of cell atypia considered to suggest cancer, to examination of sputum specimens from patients with intercurrent benign respiratory disease, and to ambiguous definition of the "gold standard" of the presence of malignant tumour.

Various "irritation" forms of the bronchial epithelium may occur in response to pathogens or irritants, ${ }^{23}$ and atypical cells have been observed in sputum from patients with bronchial asthma, bronchiectasis, prior radiotherapy, and acute and chronic respiratory infections. ${ }^{12}$ Jay et $a l^{9}$ reported that only one of their 16 subjects with false positive sputum cytology continued to shed malignant cells on repeated examinations; the remaining 15 were patients with pneumonia and the malignant cells were no longer found after recovery. Exclusion of these 15

Table 2 Reported sensitivity and specificity of sputum cytology for lung cancer

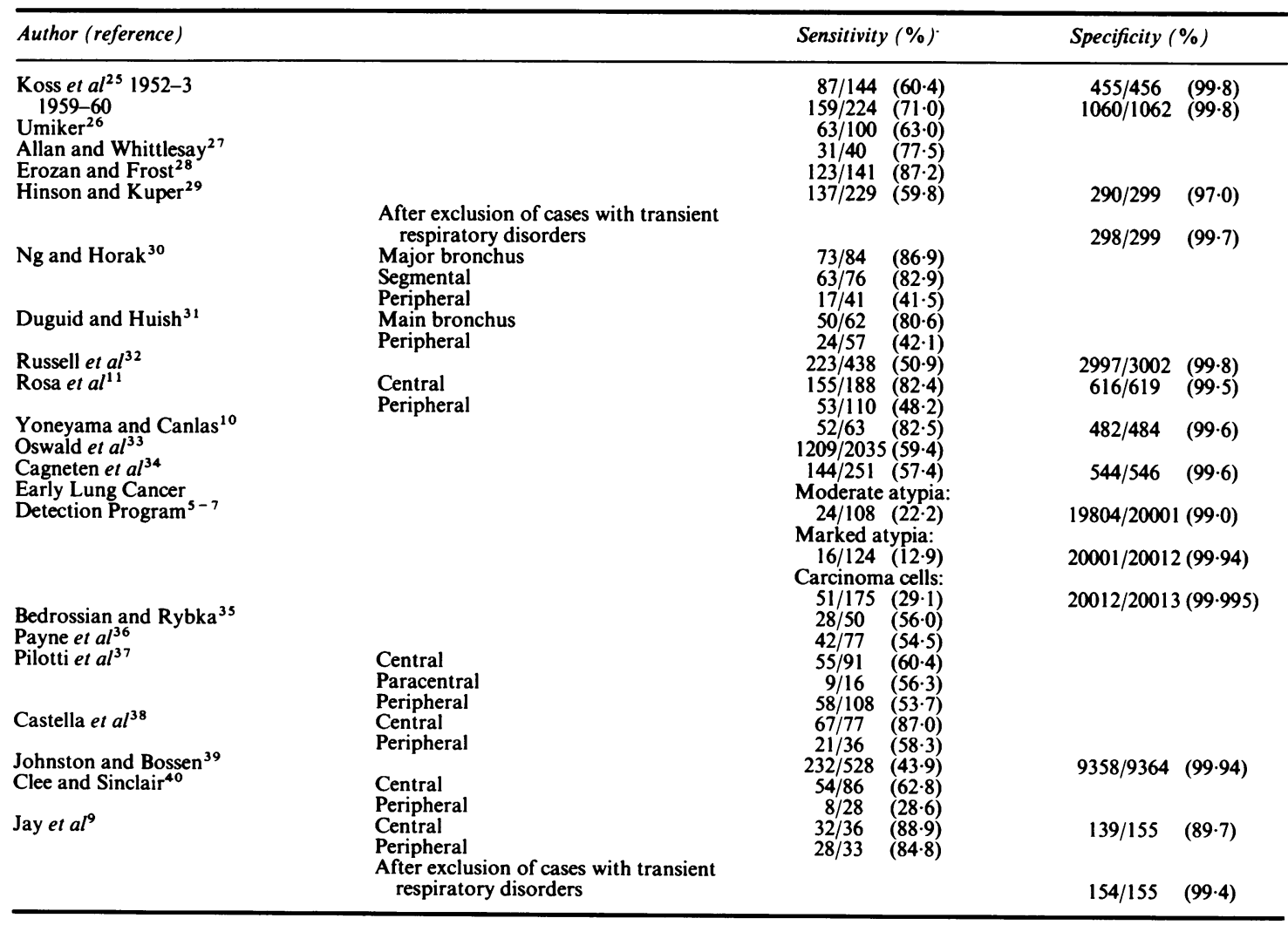


false positive results would increase the test specificity derived from their data to $99.3 \%$. Similarly, Hinson and $\mathrm{Kuper}^{29}$ reported that among nine false positive patients only one was found to shed malignant cells in repeated examinations. Exclusion of the remaining eight would increase the test specificity in Hinson's series to $99.7 \%$ (table 2).

Most of the reviewed articles define their gold standard as histologically diagnosed lung cancer after an unspecified period of follow up. Several longitudinal studies, however, have indicated that the time interval from detection of cancer cells to invasive cancer may be as long as 14 years, ${ }^{14-16}$ while the time interval from marked atypia to invasive cancer may be even longer. It is uncertain therefore whether the reported false positives were indeed cases in which malignant cells were found in the absence of lung cancer, or whether they were true positives erroneously labelled as false positives because of insufficient follow up.

\section{Prevalence of lung cancer}

The third piece of information necessary for the determination of the predictive value of a test is the prevalence of the disease in the population from which the patient is drawn ("pretest probability" or "prior probability of disease"). ${ }^{13}$ Since data on lung cancer prevalence are not available, this variable is estimated by applying the formula: prevalence $=$ incidence $\times$ average duration. ${ }^{41}$

\section{INCIDENCE OF LUNG CANCER}

Age and sex specific annual lung cancer incidence rates in Israel were drawn from the Israel Central Cancer Registry. ${ }^{42}$ The relative risk of lung cancer is about 5.0 for persons who smoke 10 cigarettes a day, 10.0 for those who smoke 20 cigarettes a day, and 20-30 for smokers of 40 or more cigarettes a day. ${ }^{43} \mathrm{~A}$ study among US veterans has also shown an 11 fold increase in risk of lung cancer among smokers. ${ }^{44}$ The estimated incidence of lung cancer in smokers and non-smokers in table 3 is based on the findings of a recent survey of Israeli adults, showing that $39.5 \%$ of $\overrightarrow{\overrightarrow{\mathrm{N}}}$ men and $23.7 \%$ of women are current cigarette smokers, ${ }^{45}$ and on the assumptions that (a) for all smokers $\frac{}{\circ}$ the relative risk of lung cancer is 10.0 and $(b)$ the $\bar{\omega}$ prevalence of smoking is the same for all age groups.

\section{AVERAGE DURATION OF THE DETECTABLE}

\section{PRECLINICAL PHASE OF LUNG CANCER}

The prevalence rate needed for the calculation of the $\vec{A}$ predictive value of sputum cytology in a person without signs or symptoms of lung cancer is the prevalence $\overrightarrow{\overrightarrow{2}}$ of detectable preclinical rather than of clinical lung $x$ cancer. The detectable preclinical phase of lung can- ? cer is a segment of the natural history of the disease $\omega$ during which the malignant growth causes no symp- $\vec{\sigma}$ toms, but its presence can be detected by the applica- 0 tion of a special diagnostic test. We do not know how long, on the average, lung cancers are both asymp- $\bar{z}$ tomatic and yet also detectable, since cancers detected in the preclinical phase are treated immediately and $\frac{\hat{\sigma}}{\sigma}$ not followed expectantly to await the development of $\vec{\oplus}$ symptoms. Nevertheless, the duration of the de- $\stackrel{\infty}{v}$ tectable preclinical phase of lung cancer can be estimated by the use of theoretical models based on rates of tumour growth, and the unique data reported by Saccomanno et al ${ }^{1415}$ in uranium miners.

According to theoretical models, ${ }^{46}$ a tumour grows $\stackrel{\circ}{\circ}$ exponentially from a single cell at a constant doubling $\varrho$ rate. This assumption predicts that a single cell of $\overrightarrow{\overrightarrow{0}}$ $10 \mu \mathrm{m}$ will develop into a tumour of $1 \mathrm{~mm}$ in diameter 3 after its volume has doubled 20 times, into a tumour of $1 \mathrm{~cm}$ after a further 10 doublings, and into a tumour of $10 \mathrm{~cm}$ (weighing $1 \mathrm{~kg}$ ) after a further $10 \risingdotseq$ doublings. Follow up measurements of lung tumour 을 diameters by serial chest radiographs has suggested a $\times$ doubling time of 88 days in squamous cell cancer, 161 윽 days for adenocarcinoma, and 29 days for small cell cancer. ${ }^{46}$ Although comprising only $33-64 \%$ of all histological types of lung cancer, ${ }^{2}$ squamous cell tumour is essentially the only histological cell type $\stackrel{\circ}{\triangle}$

Table 3 Age and sex specific annual incidence rates (per 100000 population) of cancer of the lung and bronchi by smoking habit*

\begin{tabular}{|c|c|c|c|c|c|c|}
\hline \multirow[b]{3}{*}{ Age (y) } & \multicolumn{6}{|c|}{ Annual incidence per 100000 population } \\
\hline & \multicolumn{3}{|l|}{ Men } & \multicolumn{3}{|c|}{ Women } \\
\hline & All & Non-smokers & Smokers & All & Non-smokers & Smokers \\
\hline $\begin{array}{l}50-54 \\
55-59 \\
60-64 \\
65-69 \\
70-74 \\
75+\end{array}$ & $\begin{array}{r}48 \cdot 1 \\
84.9 \\
110 \cdot 2 \\
176.9 \\
247.6 \\
283 \cdot 1\end{array}$ & $\begin{array}{r}7 \cdot 2 \\
12 \cdot 8 \\
16 \cdot 6 \\
26 \cdot 6 \\
37 \cdot 2 \\
42 \cdot 5\end{array}$ & $\begin{array}{l}110 \cdot 6 \\
195.4 \\
253 \cdot 6 \\
407 \cdot 1 \\
569.8 \\
651 \cdot 6\end{array}$ & $\begin{array}{l}16 \cdot 6 \\
33 \cdot 3 \\
31 \cdot 8 \\
50 \cdot 2 \\
60 \cdot 9 \\
80 \cdot 5\end{array}$ & $\begin{array}{l}1 \cdot 8 \\
4 \cdot 0 \\
3 \cdot 8 \\
6 \cdot 0 \\
7 \cdot 3 \\
9 \cdot 6\end{array}$ & $\begin{array}{r}63.7 \\
127.7 \\
122.0 \\
192.6 \\
233.6 \\
308.8\end{array}$ \\
\hline
\end{tabular}

*These figures apply to Israel and are compiled from references 42 and 45 . They are based on the assumptions that (a) the relative risk for lung $\sigma$ cancer in all smokers is $10 \cdot 0$ and $(b)$ the incidence of smoking in all age groups is $39 \cdot 5 \%$ for men and $23 \cdot 7 \%$ for women. 
Table 4 Distribution of histological types of radiologically occult lung cancer detected by pulmonary cytology (numbers with percentages in parentheses)

\begin{tabular}{|c|c|c|c|c|c|c|}
\hline Author & $\begin{array}{l}\text { Squamous cell } \\
\text { carcinoma }\end{array}$ & Adenocarcinoma & $\begin{array}{l}\text { Large cell } \\
\text { carcinoma }\end{array}$ & $\begin{array}{l}\text { Oat cell } \\
\text { carcinoma }\end{array}$ & $\begin{array}{l}\text { Not } \\
\text { classified }\end{array}$ & Total \\
\hline 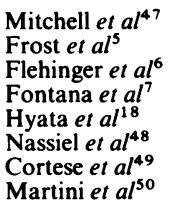 & $\begin{array}{r}7(58) \\
11(100) \\
9(100) \\
15(88) \\
27(84) \\
23(88) \\
54(100) \\
43(93)\end{array}$ & $\begin{array}{l}0 \\
0 \\
0 \\
0 \\
4(13) \\
3(12) \\
0 \\
3(7)\end{array}$ & $\begin{array}{l}0 \\
0 \\
0 \\
2(12) \\
0 \\
0 \\
0 \\
0\end{array}$ & $\begin{array}{ll}2(17) \\
0 & \\
0 & \\
0 & \\
1 & (3) \\
0 & \\
0 & \\
0 & \end{array}$ & $\begin{array}{l}3(25) \\
0 \\
0 \\
0 \\
0 \\
0 \\
0 \\
0\end{array}$ & $\begin{array}{r}12(100) \\
11(100) \\
9(100) \\
17(100) \\
32(100) \\
26(100) \\
54(100) \\
46(100)\end{array}$ \\
\hline
\end{tabular}

detectable by sputum cytology in subjects with normal chest radiographs (table 4). Squamous cell cancer often originates centrally and grows as a thin sheet replacing the mucosa, thus escaping radiographic detection but readily shedding malignant cells into the sputum. ${ }^{5}$ For squamous cell cancer, the duration of the total preclinical phase-that is, from the first cell division to the earliest possible radiograph diagnosis ( $1 \mathrm{~cm}$ tumour diameter) is 7.2 years ( 30 doublings); to the time of usual diagnosis ( $3 \mathrm{~cm}$ tumour diameter) it is 8.4 years ( 35 doublings); and to death $(10 \mathrm{~cm}$ in tumour diameter) it is $\mathbf{9 \cdot 6}$ years ( 40 doublings).

We do not know the minimum tumour size needed to shed malignant cells into the sputum. Assuming that exfoliation of malignant cells begins when the tumour has a $1 \mathrm{~mm}$ diameter, it would take 10 doublings or 2.4 additional years to reach the minimum detectable size by chest radiograph $(1 \mathrm{~cm})$. On the assumption that exfoliation begins when the tumour consists of 1000 cells only, it would take 20 doublings, or 4.8 years, for the tumour to reach the minimum detectable size radiographically.

There have been sporadic studies of persons in whom the transition from marked atypia to histologically confirmed lung cancer occurred after a delay of from 6 months to 14 years. ${ }^{1622}$ These reports indicate that the duration of the detectable preclinical phase of lung cancer is highly variable, probably because of differences in tumour growth rates. We know of only one systematic cytological follow up of a high risk population from which the duration of the detectable preclinical phase of lung cancer can be estimated. In their initial ${ }^{14}$ and updated ${ }^{15}$ report, Saccomanno et al described the follow up of 38 uranium miners who developed invasive squamous cell lung cancer after an average duration of mild atypia of $\mathbf{2 . 8}$ years, of moderate atypia of 4.2 years, of marked atypia of 1.2 years, and of carcinoma in situ of 3.26 years. If we define the detectable presymptomatic phase of lung cancer as the period during which cells with marked atypia or carcinoma cells are shed by a symptomless person with a normal chest radiograph, then the lead time from detection of cells with marked atypia to invasive cancer calculated from these data is 4.48 years, while the average interval from first detection of carcinoma cells to tumour detection is 3.26 years. These values are consistent with those deduced from the theoretical model above.

\section{Positive predictive value of sputum cytology}

Additional studies are needed to define better the reliability of sputum cytology and the false positive rate relative to an undisputed gold standard. We consider, however, that our survey of published data justifies the following assumptions as a basis for an estimate of the probability of lung cancer in a 60 year old nonsmoking woman with bronchial asthma and a normal chest radiograph. The assumptions were deliberately biased towards an overestimate of the probability of lung cancer.

(1) The risk of cancer in a smoker is 10 times that of a non-smoker. ${ }^{4344}$

(2) The risk of lung cancer in a patient with bronchial asthma is the same as that in patients of the same sex, age, and smoking habit without bronchial asthma.

(3) The sensitivity of sputum cytology for lung cancer is $88.9 \%$. $^{9}$

(4) The specificity of sputum cytology is $99.94 \%$ for marked atypia and $99.99 \%$ for carcinoma cells. ${ }^{5-7}$

(5) The duration of the detectable preclinical phase of squamous cell lung cancer is 3.26 years from detection of cancer cells and 4.48 years from detection of cells with marked atypia in the sputum. ${ }^{15}$

(6) Reported limitations of the reproducibility of sputum cytological findings ${ }^{24}$ are ignored.

(7) A repeated finding of malignant cells in the sputum excludes the possibility that the cytological abnormality is due to a transient response to irritation in a subject with bronchial asthma. ${ }^{29}$

\section{CAlCulation OF POSITIVE PREDictive}

\section{VALUE OF SPUTUM CYTOLOGY}

Before the cytological examination, the patient described in the introduction to this paper had no manifestations that would increase the likelihood of lung cancer beyond that expected from the prevalence of 
Table 5 Two by two table showing calculation of positive predictive value of sputum cytology based on sensitivity of $88.9 \%$, specificity of $99.94 \%$, and pretest probability (prevalence) of 17.0/100000 in a hypothetical test population of 100000 persons

Disease state:

\begin{tabular}{|c|c|c|c|c|}
\hline \multirow{3}{*}{$\begin{array}{l}\text { Cytology } \\
\text { results: }\end{array}$} & & $\begin{array}{l}\text { Preclinical } \\
\text { lung cancer }\end{array}$ & Not cancer & Total \\
\hline & Positive & $15 \cdot 1$ & $60 \cdot 0$ & $75 \cdot 1$ \\
\hline & Negative & 1.9 & 99923.0 & $99924 \cdot 9$ \\
\hline & Total & $17 \cdot 0$ & 99983.0 & $100000 \cdot 0$ \\
\hline
\end{tabular}

the disease in her age group of non-smokers. Therefore, at any time, in a hypothetical population of 100000 non-smoking 60 year old women, there would be 17.0 cases of detectable preclinical lung cancer (the prevalence rate). Thus, the pretest probability of lung cancer would be 17.0/100000 (obtained by multiplying the incidence rate in a non-smoking 60 year old woman, $3 \cdot 8 / 100000$ (table 3 ), by the estimated duration of detectable preclinical disease from exfoliation of cells with marked atypia to detection of lung cancer -4.48 years). The remainder of the population, 99983 women, would not have detectable preclinical disease. If we assume the highest reported sensitivity of sputum cytology $(88.9 \%), 15.1$ of the 17 cases would have positive test results $(88.9 \%$ of 17.0 $=15 \cdot 1)$. The remaining 1.9 women with disease would have negative results (the "false negatives"). Similarly, if we assume the highest reported specificity of cells with marked atypia (99.94\%), then 99923 of the 99983 subjects (that is, $99.94 \%$ of 99983 ) would have negative results, and the remaining 60 subjects without disease would have positive results (the "false positives"). These relationships are shown in table 5.

The positive predictive value, which is defined as the proportion of all positive responders who actually have disease, is then calculated by dividing the $15 \cdot 1$ true positives by the total number of positives, $75 \cdot 1$; the result is $\mathbf{0} \cdot 201$. The meaning of this result in the clinical situation is that there is a $20 \cdot 1 \%$ likelihood that a non-smoking 60 year old woman with positive sputum cytological findings actually has lung cancer.

If carcinoma cells (rather than markedly atypical cells) were found in her sputum, a finding with the still higher specificity of $99 \cdot 99,5^{5-7}$ the likelihood of cancer would be $52.6 \%$. On the other hand, a male smoker of the same age with cancer cells in the sputum would have an estimated pretest probability of detectable preclinical lung cancer of 836.9/100000 (253.6 × 3.3), and in such a case the positive predictive value of . malignant cells in the sputum would be $98 \cdot 7 \%$.
IMPLICATIONS FOR SCREENING FOR LUNG

CANCER

Exfoliative sputum cytology is not a definitive diagnostic test for lung cancer. As in the case of all diag- $\frac{\bar{\partial}}{\vec{*}}$ nostic aids, its positive predictive value depends not $\frac{\bar{\sigma}}{\vec{D}}$ only on its sensitivity and specificity but also on the $\stackrel{\mathbb{Q}}{\square}$ pretest probability of the disease. As in all other tests, ๗ when the pretest likelihood of disease is low, a posi- $\vec{A}$ tive result is not particularly helpful in confirming the disease, since the false positive results outnumber true $\overrightarrow{\vec{\omega}}$ positives. On the other hand, in a high risk population a finding of even moderate atypia might have a strong $\overrightarrow{\vec{x}}$ positive predictive value for lung cancer. The decision on whether or not to do a cytological examination of $\frac{N}{\omega}$ the sputum should be based on the prior estimate of $\vec{\overrightarrow{ }}$ the likelihood of lung cancer given the patient's risk o indicators, symptoms, and signs.

Should this middle aged, non-smoking woman with bronchial asthma have had her sputum examined cy- 3 tologically to detect early pulmonary cancer? The results of recent studies do not provide definitive and $\stackrel{\supset}{\supset}$ conclusive evidence that early diagnosis of lung can- $\vec{\oplus}$ cer reduces the mortality from this disease. ${ }^{51-53}$ The $\stackrel{\infty}{v}$ inverse correlation between survival after surgical re- 0 section of lung cancer and stage of the tumour may be due merely to lead time or sampling biases. ${ }^{8}$ Screening for lung cancer therefore is not specifically recommended unless performed in the context of an $\Phi$ experimental trial. ${ }^{54}$ What is the threshold of the pretest probability of presymptomatic lung cancer that would justify screening by sputum cytology in such trials? We have no ready answer to this question. The decision should be based on the trade off between the possible (but so far unproved) benefit from early surgical resection of lung cancer and the cost of screening plus harm inflicted on patients with false positive re- $\stackrel{x}{\circ}$ sults in terms of anxiety, morbidity, and mortality from subsequent examinations and surgery. As with every other test, cytological examination of the $₹$ sputum should be undertaken-both in the setting of $\mathrm{O}$ a screening trial and in diagnostic investigation of individuals - only if its estimated positive predictive $\frac{0}{2}$ value is considered sufficiently high for a positive result to bring about a change in the patient's of management.

JOCHANAN BENBASSAT N

Department of Medicine N

Hadassah University Hospital at Mount Scopus ARIEH REGEV

Hadassah Medical School $\stackrel{\circ}{\frac{0}{(}}$ (medical student) $\stackrel{\oplus}{+}$

Hebrew University $\square$

PAUL E SLATER $\overline{0}$

Department of Medical Ecology $\overparen{\mathbb{Q}}$

Hadassah School of Public Health $\overrightarrow{\mathbb{D}}$ and Community Medicine Hebrew University Jerusalem, Israel 


\section{References}

1 Fraser RG, Pare JAP, eds. Diagnosis of diseases of the chest. Philadelphia: WB Saunders, 1977.

2 DeVita VT, Hellman S, Rosenberg SA, eds. Cancer: principles and practice of oncology. 2nd ed. Philadelphia: JB Lippincott, 1985.

3 Silverberg E. Cancer statistics. CA 1984;35:7-23.

4 Berlin NI, Buchner CR, Fontana RS, Frost JK, Melamed MR. The national Cancer Institute Cooperative Early Lung Cancer Detection Programs: results of the initial screen (prevalence): early lung cancer detection: introduction. Am Rev Respir Dis 1984; 130:545-9.

5 Frost JK, Ball WC, Levin ML, et al. Early lung cancer detection: results of the initial (prevalence) radiologic and cytologic screening in the John Hopkins study. Am Rev Respir Dis 1984;130:549-54.

6 Flehinger BJ, Melamed MR, Zaman MB, Heelan RT, Perchick WB, Martini N. Early lung cancer detection: results of the initial (prevalence) radiologic and cytologic screening in the Memorial Sloan Kettering study. Am Rev Respir Dis 1984;130:555-60.

7 Fontana RS, Sanderson DR, Taylor WF, et al. Early lung cancer detection: results of the initial (prevalence) radiologic and cytologic screening in the Mayo Clinic study. Am Rev Respir Dis 1984;130:561-5.

8 Anonymous. Early lung cancer detection: summary and conclusions. Am Rev Respir Dis 1984;130:565-70.

9 Jay SJ, Wehr K, Nicholson DP, Smith AL. Diagnostic sensitivity and specificity of pulmonary cytology. Acta Cytol 1980;24:304-12.

10 Yoneyama T, Canlas MS. From exfoliative to diagnostic cytology: A statistical evaluation of pulmonary cytology. Acta Cytol 1978;22:158-61.

11 Rosa UW, Prolla JC, Gastal ES. Cytology in diagnosis of cancer affecting the lung. Results of 1000 consecutive patients. Chest 1973;63:203-7.

12 Spriggs AI, Cole M, Dunnill MS. Alveolar cell carcinoma: a problem in sputum cytodiagnosis. J Clin Pathol 1982;35:1370-9.

13 Griner PF, Mayevski RJ, Mushlin AI, Greenland P. Selection and interpretation of diagnostic tests and procedures. Ann Intern Med 1981;94:553-600.

14 Saccomanno G, Archer VE, Auerbach O, Saunders RP, Brennan IM. Development of carcinoma in the lung as reflected in exfoliated cells. Cancer 1974;33:256-69.

15 Saccomanno G. The contribution of uranium miners to lung cancer histogenesis. Rec Res Canc Res 1982; 82:43-52.

16 Nassiel M, Carlini E, Aner G. Pathogenesis of bronchial cancer with special reference to morphogenesis and the influence on the bronchial mucosa of 20-methylcholantrene and cigarette smoking. Rec Res Canc Res 1982;82:53-66.

17 Saffiotti U, Montesano R, Sellakumar AR. Experimental cancer of the lung. Inhibition by Vitamin A of the induction of tracheobronchial squamous cell tumor. Cancer 1967;20:857-70.

18 Hayata Y, Funatsu H, Kato H, Saito Y, Sawamura K, Furose K. Results of lung cancer screening programs in Japan. Rec Res Canc Res 1982;82:163-73.
19 Kotin P, Paul W. Results of a lung cancer detection program in an asbestos industry. Rec Res Canc Res 1982;82:131-9.

20 Kobusch AB, Simard A, Feldstein M, Vanclair R, Gibbs GW, Bergeron F, Morissette N, Gavis R. Pulmonary cytology in chrysotile asbestos workers. J Chron Dis 1984;37:599-607.

21 Band P, Feldstein M, Saccomanno G, Watson L, King G. Potentiation of cigarette smoking and radiation. Cancer 1980;45:1273-7.

22 Band B, Feldstein M, Watson L, King G, Saccomanno G. Lung cancer screening program in Canadian uranium mines. Rec Res Canc Res 1982;82:153-7.

23 Johnston WW, Frable WJ. The cytopathology of the respiratory tract. A Review. Am J Pathol 1976; 84:372-424.

24 Evans DMD, Shelley G. Respiratory cytodiagnosis: study in observer variation and its relation to quality of material. Thorax 1982;37:259-63.

25 Koss LG, Melamed MR, Goodner JT. Pulmonary cytology. Acta Cytol 1964;8:104-13.

26 Umiker WO. Diagnosis of bronchogenic carcinoma: an evaluation of pulmonary cytology, bronchoscopy and scalene lymph node biopsy. Dis Chest 1960;37:82-5.

27 Allan WB, Whittlesay P. The results of the experimental use of sulfur dioxide in the production of material for cell studies in lung cancer. Ann Intern Med 1960;52:326-30.

28 Erozan YS, Frost JK. Cytopathologic diagnosis of cancer in pulmonary material: a critical histopathologic correlation. Acta Cytol 1970;14:560-5.

29 Hinson KFW, Kuper SWA. The diagnosis of lung cancer by examination of sputum. Thorax 1963; 18:350-9.

$30 \mathrm{Ng}$ ABP, Horak GC. Factors significant in the diagnostic accuracy of lung cytology. Acta Cytol 1983; 27:397-406.

31 Diguid HLD, Huish DWI. Clinical evaluation of cytodiagnosis in bronchial carcinoma. $B r$ Med $J$ 1963; ii:287-91.

32 Russell WO, Neidhart HW, Mountain CF, Griffith KM, Chang JR. Cytodiagnosis of lung cancer. A report of four year laboratory, clinical and statistical study with a review of the literature on lung cancer and pulmonary cytology. Acta Cytol 1963;7:1-44.

33 Oswald NC, Hinson KFW, Canti G, Miller AB. The diagnosis of primary lung cancer with special reference to sputum cytology. Thorax 1971;26:623-31.

34 Cagneten CB, Geller CE, Saenz MC. Diagnosis of bronchogenic carcinoma through cytological examination of the sputum. Acta Cytol 1976;20:530-6.

35 Bedrossian CWM, Rybka DL. Bronchial brushing during fiberoptic bronchoscopy for the cytodiagnosis of lung cancer: Comparison with sputum and bronchial washings. Acta Cytol 1976;20:446-53.

36 Payne CR, Stovin PG, Barker V, McVittie S, Stark JE. Diagnostic accuracy of cytology and biopsy in primary bronchial carcinoma. Thorax 1979;34:294-9.

37 Pilotti S, Rilke F, Gribaudi G, Ravasi GL. Sputum cytology for the diagnosis of carcinoma of the lung. Acta Cytol 1982;26:649-54.

38 Castella J, de la Heras P, Puzo C, Martinez C, Lopez A, 
Cornudella R. Cytology of postbronchoscopically collected sputum samples and its diagnostic value. Respiration 1981;42:116-21.

39 Johnston WW, Bossen EH. Ten years of respiratory cytopathology at Duke University Medical Center. I. The cytopathologic diagnosis during the years 1970-74. Acta Cytol 1981;25:103-7.

40 Clee MD, Sinclair DJM. Assessment of factors influencing the results of sputum cytology of bronchial carcinoma. Thorax 1981;36:143-6.

41 Lilienfeld AM, Lilienfeld DE. Foundations of epidemiology. 2nd ed. London: Oxford University Press, 1980:139.

42 Katz L, Steinitz R. Cancer Incidence in Israel. In: Waterhouse J, Muir C, Shanmugaratnam K, Powell J, eds. Cancer incidence in five continents. Vol 4. Lyon: International Agency for Research on Cancer, 1982:400-1.

43 Doll R, Hill AB. Mortality in relation to smoking: 10 years observation of British doctors. $\mathrm{Br}$ Med $\mathrm{J}$ 1964;ii:1399-410.

44 Rogof E, Murray JL. Smoking and causes of death among US veterans, 16 years of observation. Public Health Reports 1980;95:213-22.

45 Gofin R, Kark JD, Friedlander Y. Cigarette smoking, blood pressure and pulse rate in the Jerusalem Lipid Research Clinic Prevalence Study. Isr J Med Sci 1982;18:1217-22.
46 Geddes DM. The natural history of lung cancer. A review based on rates of tumour growth. $\mathrm{Br} J$ Dis Chest 1979;73:1-17.

47 Mitchell DM, Emerson CJ, Collyer J, Collins JV. Fiberoptic bronchoscopy: ten years on. $\mathrm{Br}$ Med $J$ 1980;281:360-3.

48 Nassiell M, Kinman J, Haglund S, Roger V, Nassiell K. $\stackrel{\mathbb{8}}{\stackrel{8}{8}}$ Detection of early roentgenologically occult bronchogenic carcinoma. Rec Res Canc Res 1982;82: $159-62$.

49 Cortese DA, Pairolero PC. Roentgenologically occult $\overrightarrow{\vec{H}}$ lung cancer. $J$ Thorac Cardiovasc Surg 1983;86: 373-80.

50 Martini N, Melamed MR. Occult cancer of the lung. Ann Thorac Surg 1980;30:215-21.

51 Eddy DM. Finding cancer in asymptomatic people. Cancer 1983;51:2440-5.

52 Levin ML, Tockman MS, Frost JK, Ball WC. Lung $\vec{S}$ cancer mortality in males screened by chest radiograph $ᄋ$ and cytologic sputum examination. Rec Res Canc Res 1982;82:138-46.

53 Sanderson D, Fontana R. Results of the Mayo lung project: an interim report. Rec Res Canc Res $\stackrel{\rho}{工}$ 1982;82:179-86.

54 Seidenfeld JJ. Screening for bronchogenic carcinoma. Ann Intern Med 1985;102:851-2. 


\section{Corrections}

\section{Predictive value of sputum cytology}

The paper by Dr J Benbassat and others (March 1987;42:165-72) contained miscalculations in two areas. The first relates to the calculated age and sex specific annual incidence rates (per 100000 population) of cancer of the lung and bronchi by smoking habit in table 3 . This should read as in the table below.

The second error relates to the calculation of the prevalence of presymptomatic squamous cell lung cancer in the population. In calculating it the authors did not consider the fact that almost all occult cancers are squamous eell cancer, which comprises only $40-60 \%$ of all histological types of lung cancers. Thus the correct calculation of the pretest probability of squamous cell lung cancer in a 60 year old non-smoking woman would be $10 \cdot 2$ (incidence of lung cancer in general per 100000 non-smoking women aged 60-64) divided by 2 (to obtain the incidence of squamous cell cancer) and multiplied by $\mathbf{4 . 4 8}$ years (the estimated duration of detectable preclinical disease from exfoliation of cells with marked atypia to detection of lung cancer), which equals $22 \cdot 8 / 100000$. The corrected likelihood that a non-smoking 60 year old woman with positive sputum cytology actually has lung cancer is therefore $24.9 \%$ and not $20.1 \%$ as erroneously calculated in the paper.

The authors point out that these corrections do not invalidate their conclusion that exfoliative sputum cytology is not a definitive diagnostic test for lung cancer.

Age and sex specific annual incidence rates (per 100000 population) of cancer of the lung and bronchi by smoking habit*

\begin{tabular}{|c|c|c|c|c|c|c|}
\hline \multirow{3}{*}{$\begin{array}{l}\text { Age } \\
(y)\end{array}$} & \multicolumn{6}{|c|}{ Annual incidence per 100000 population } \\
\hline & \multicolumn{3}{|l|}{ Men } & \multicolumn{3}{|c|}{ Women } \\
\hline & All & Non-smokers & Smokers & All & Non-smokers & Smokers \\
\hline $\begin{array}{l}50-54 \\
55-59 \\
60-64 \\
65-69 \\
70-74 \\
75+\end{array}$ & $\begin{array}{r}48.1 \\
84.9 \\
110.2 \\
176.9 \\
247.6 \\
283.1\end{array}$ & $\begin{array}{l}10 \cdot 6 \\
18 \cdot 6 \\
24 \cdot 2 \\
38 \cdot 8 \\
54 \cdot 4 \\
62 \cdot 2\end{array}$ & $\begin{array}{l}105.6 \\
186.4 \\
241.9 \\
388.4 \\
543.6 \\
621.5\end{array}$ & $\begin{array}{l}16 \cdot 6 \\
33 \cdot 3 \\
31 \cdot 8 \\
50 \cdot 2 \\
60.9 \\
80.5\end{array}$ & $\begin{array}{r}5 \cdot 3 \\
10 \cdot 6 \\
10 \cdot 2 \\
16 \cdot 0 \\
19 \cdot 4 \\
25 \cdot 7\end{array}$ & $\begin{array}{r}53.0 \\
106.3 \\
101.5 \\
160.2 \\
194.4 \\
256.9\end{array}$ \\
\hline
\end{tabular}

*These figures apply to Israel and they are based on the assumptions that $(a)$ the relative risk for lung cancer in all smokers is $10 \cdot 0$, and $(b)$ the incidence of smoking in all age groups is $39.5 \%$ for men and $23.7 \%$ for women.

\section{Rapid diagnosis of sputum negative miliary tuberculosis using the fexible fibreoptic bronchoscope}

In the letter by Dr WS Kwee (May 1987;42:399-400) the first sentence on page 400 should read "Twenty one cases were diagnosed by this combination of $Z N$ (12 positive cases) and AR (19 positive cases) staining techniques...."
Role of the neodymium YAG laser in the management of tracheal tumours

Reprints of the paper by Dr PJM George and others (June $1987 ; 42: 440-4)$ are available; we regret it is stated that they are not.

\section{Notices}

\section{Epidemiology and medical statistics course}

An intensive course in epidemiology and medical statistics will be held at the Cardiothoracic Institute, Brompton Hospital, from 26 to 30 October 1987 (course fee £20). Inquiries to postgraduate course secretary, Cardiothoracic Institute, Fulham Road, London SW3 6HP (01 3528121 ext 8003).

\section{Symposium on cardiorespiratory emergencies}

The Fourth International Symposium on Cardiorespiratory Emergencies will be held from 16 to 20 November 1987 at the Doelen Concert Hall, Rotterdam, The Netherlands. Tutorials, exhibits, and posters as well as scientific papers will be included. Further information from Dr Omar Prakash, Erasmus University, PO Box 1738, 3000 DR Rotterdam, The Netherlands (tel 010-4635212; telex 25267). 